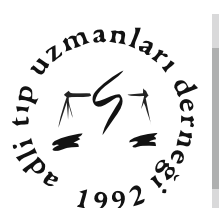

1992

\title{
1306 Nazal Kırıkı Olgunun Adli Rapor Sürecinin Değerlendirilmesi
}

\section{The Evaluation of Judicial Report Process of 1306 Patients with Nasal Fracture}

\author{
Kenan Karbeyaz ${ }^{1}$, Selma Düzer ${ }^{2}$, Sertaç Düzer ${ }^{3}$, Yasemin Balci ${ }^{4}$ \\ ${ }^{1}$ Adli Tip Şube Müdürlüğü, Eskisehir \\ ${ }^{2}$ Adli Tıp Şube Müdürlüğ̈̈, Elazığ \\ ${ }^{3}$ Eğitim ve Araștırma Hastanesi, Elazığ

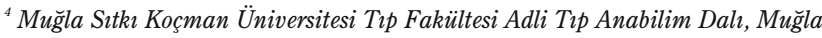

\section{Özet}

Amaç: Yüz bölgesine gelen travmalarda anatomik yapısı veyerleşimi nedeniyle en sık burun kemiği kırıklarıgörülmektedir. Adli tıp şube müdürlüklerine yansıyan nazal kırıklı olgularda, rapor düzenleme aşamasında sıkıntılar yaşanmaktadır. Bu çalışmada, burun kemik kırıklarının adli travmatoloji açısından değerlendirilmesi ve raporlama aşamasında yaşanan aksaklıkların vurgulanması amaçlanmıştır.

Gereç ve Yöntem: 01 Haziran 2011-31Mayıs 2014 tarihleri arasında Eskişehir Adli Tıp Şube Müdürlüğü’nce düzenlenen 24306 adli rapordan, burun kemiği kırığı saptanan 1306olgu retrospektif olarak incelenerek değerlendirme kapsamınaalındı.

Bulgular: 1306 olguya, travma ağırlığ 1 açısından rapor düzenleyebilmek için toplam, 2104 yazışma yapılmıştır. 764 olguda 1 kez, 17 olguda $2 \mathrm{kez}$ olmak üzere ek belge, grafi veya konsültasyon istenilmiştir. Olguların yaş ve cinsiyetleri literatürle uyumlu bulunmuştur.

Sonuç: Uzun vadede, sağlık kuruluşlarında adli tıp uzmanı istihdamının artırılması, kısa vadede ise illerde sağlık kuruluşlarına ait veri sistemlerine adli tıp şube müdürlüklerinin de entegre edilmesi gerektiği sonucuna varılmıştır.

Anahtar kelimeler: Nazal kırık, Adli rapor, Travma.

\section{Giriş}

Dıştan veya içten gelen zorlamalarla kemiğin anatomik bütünlügüüün bozulmasına kırık adı verilmektedir(1). Yüz bölgesine gelen travmalarda anatomik yapısı ve yerleşimi nedeniyle en sık burun kemiği kırıkları görülmektedir (2-6). Burun kemik kırı̆̆ının tipi;uygulanan kuvvetin şiddetine, yönüne ve yaralanmanın mekanizmasına bağlıdır $(7,8)$. Burun kemikleri herhangi bir yüz kemiğinin kırılmasina neden olabilecek kuvvetten daha az şiddette bir kuvvetle kırılabilir (38). Yaralanmalarda vücutta oluşan kırkklar, yeni Türk Ceza Kanunu'nun "netice itibariyle ağırlaşmış yaralanmalara verilecek cezaların düzenlendiği 87. maddesinin 3. Fıkrasında ayrı bir kavram olarak yer almaktadır. İlgili fikrada kırığın,

Sorumlu Yazar: Doç. Dr. Kenan Karbeyaz

Adli Tip Şube Müdürlüğü, Eskişehir

E-mail: drkenankarbeyaz@hotmail.com

\section{Abstract}

Objective: Nasal fracture is frequently seen in facial region traumas due to its anatomical properties and location. Some problems are encountered during report process of nasal fracture patients in Judicial Medicine Director Office. In this study, we have aimed to emphasize the evaluation of nasal fractures for judicial traumatology and the any problem during judicial report process.

Materials and methods: Between 01 June 2011 and 31 May 2014, 24306 judicial report which ordered by Eskişehir Judicial Medicine Director Office were investigated and then, 1306 patients with nasal fracture were evaluated retrospectively and included to the study.

Results: Totally 2104 correspondences were performed for report preparation according to trauma's degree in 1306 patients. Additional document, graphy and consultation were requestedonce in 764 patients and twice in 17 patients. The ages and sex of the patients were found similar with the literature.

Conclusion: We concluded that the employment of Judicial Medicine Specialists should be increased in health institutions in long term and judicial medicine director offices should be integrated to the databases of health institutions in cities in short-term.

Keywords: Nasal fracture, Judicial report, Trauma. öngörülmektedir.

Adli Tip Kurumu Başkanlığı, Adli Tip Uzmanları Deneği ve Adli Tip Derneği'nce, yeni Türk Ceza Kanunu çerçevesinde düzenlenecek adli raporlar için hazırlanan kılavuzda, kırılan her kemiğe, uluslar arası kısaltılmış yaralanma cetveli (Abbreviated Injury Scale, AIS) ile uyumlu olması gözetilerek bir ağırlık puanı verilmiştir. Buna göre;burun kemiğinde ayrıksız, ayrıklı lineer kırık, uç kırı̆̆ı bir puan, burun kemiğinde parçalı kırık iki puan olarak belirlenmiştir (9).

Adli tıp şube müdürlüklerinde, adli rapor düzenlenirken çoğu kez hastane evrakları esas alınmaktadır. Ancak burun kemik kırıklarında, kırı̆̆ın tespit edilmesi, kırığın tipinin yazılması veya görüntüleme yöntemlerine ait sonuçların paylaşılmasında aksaklıklar yaşandığı görülmüştür. Bu çalışmada, burun kemik kırıklarının adli travmatoloji açısından değerlendirilmesi ve raporlama aşamasında yaşanan aksaklıkların vurgulanması amaçlanmıştır. 


\section{Gereç ve Yöntem}

01 Haziran 2011-31Mayıs 2014 tarihleri arasında Eskişehir Adli Tıp Şube Müdürlüğü’nce düzenlenen 24306 adli rapordan, burun kemiği kırığı saptanan 1306olgu retrospektif olarak incelenerek değerlendirme kapsamına alındı.

Olgular yaş, cinsiyet, oluş nedeni, burun kemiği kırığının tipi ve kırığın hayat fonksiyonlarına etkisi yönünden incelendi Olgulara kati rapor düzenlenme aşamasına kadar kaç kez müzekkere istenildiği ve sebepleri incelendi. Çoklu travması olan olgularda, diğer yaralanmalar göz ardı edilerek, olguların burun kırıkları değerlendirmeye alındı. Veriler SPSS 18 programı kullanılarak değerlendirildi.

\section{Bulgular}

1306 olguya travma ă̆1rlı̆g 1 açısından rapor düzenleyebilmek için toplam 2104yazışma yapılmıştır. 764 olguda $(\%$ 58,5) 1 kez ek yazışma yapılmıştır. Bu olgulardan 437'sinin $(\% 33,5)$ ön raporunda kırık şüphesi olduğu belirtilmiş başka bilgi verilmemiştir. 325 olguda (\% 24,9) kırık olduğu kaydedilmiş ancak tipi belirtilmemiştir. $\mathrm{Bu}$ incelemeler sırasında 327'sinde (\% 24,9) ön raporda kırık olduğu yazılmış, ancak kırığın türü belirtilmemiştir. Bu olgularda, hastanın tüm grafileri veya bunlara ait raporlar ile olayla ilgili tedavi gördüğü sağlık kuruluşundan tüm tıbbi belgelerinin veya hastane dosyasının tarafımıza gönderilmesi istenilmiştir. Ayrıca bu olguların 14'ünden konsültasyon da istenilmiştir.
17 (\% 1,3) olguda 2 kez ek yazışma yapılmıştır. Bunların 5 ’inde $(\% 0,4)$ gönderilen bilgiler yeterli olmayıp, kırı̆̆ın olup olmadığı veya türü açısından konsültasyona ihtiyaç duyulmuştur. 12'sinde $(\% 0,9)$ ilk yazışmada istenilen hastane dosyası veya grafilerin eksik gönderilmesi nedeniyle tekrar yazışma yapılmıştır. 525 olguda (\% 40,2) ilk düzenlenen raporlar, grafiler ve/veya grafilere ait raporlar tarafımıza eksiksiz olarak gönderilmiş ve direk olarak kesin rapor düzenlenebilmiştir. Toplam 19 olguda (\% 1,5) tıbbi belgeler, grafiler veya tomografiler tarafımızca incelenmiş ancak sonuca varabilmek için Kulak Burun Boğaz uzmanı konsültasyonuna ihtiyaç duyulmuştur. Çalışma sırasında 155 olguda burun kırı̆̆g olmadı anlaşılmış ve çalışma kapsamından tamamen çıkarılmıştır.

Olguların 203’ünün kadın (\% 15,5), 1103’ünün erkek (\% $84,5)$ olduğu belirlenmiştir. Olguların en küçüğü 13, en büyüğü 71 yaşında olup, yaş ortalamasının $35,3 \pm 11,6$ olduğu belirlenmiştir (Tablo 1). Yaş gruplarının, cinsiyete göre dağılımında anlamlı bir ilişki saptanmıştır. 18 yaş ve altındaki olgularda erkeklerin belirgin olarak daha fazla olduğu belirlenmiştir $(\mathrm{P}<0,0001)$. Nazal kemik kırıklarında en sık nedeninin künttravmatik etkili eylem olduğu (n=783, \% 60,0) ikinci sırada trafik kazası olduğu (n=391, \% 29,9) belirlendi. Kırık nedenlerinin cinsiyete göre dağılımı incelendiğinde, kadınlarda burun kırığının en sık nedeninin trafik kazası olduğu, erkeklerde ise en sık künt travmatik etkili eylem sonucu burun kemiğinin kırıldığı saptandı (Tablo 1, $\mathrm{P}<0,0001$ ).

Tablo 1. Olguların yaş gruplarının ve kırık nedenlerinin cinsiyete göre dağılımları.

\begin{tabular}{|c|c|c|c|c|c|c|c|}
\hline \multirow{3}{*}{ Yaş grubu } & \multicolumn{4}{|c|}{ Cinsiyet } & \multicolumn{3}{|c|}{ Toplam } \\
\hline & \multicolumn{2}{|c|}{ Erkek } & \multicolumn{2}{|c|}{ Kadın } & \multirow[t]{2}{*}{$\mathbf{n}$} & \multirow[t]{2}{*}{$\%$} & \\
\hline & n & $\%$ & $\mathbf{n}$ & $\%$ & & & \\
\hline 18 ve alt 1 & 275 & 24,9 & 9 & 4,4 & 284 & 21,7 & \multirow{5}{*}{$\chi^{2}=59,547$} \\
\hline $19-29$ & 462 & 41,9 & 108 & 53,2 & 570 & 43,6 & \\
\hline $30-39$ & 205 & 18,6 & 67 & 33,0 & 272 & 20,8 & \\
\hline $40-49$ & 113 & 10,2 & 11 & 5,4 & 124 & 9,5 & \\
\hline 50 ve uistii & 48 & 4,4 & 8 & 3,9 & 56 & 4,4 & \\
\hline Toplam & 1103 & 100,0 & 203 & 100,0 & 1306 & 100,0 & \\
\hline \multicolumn{8}{|l|}{ Kırı̆̆ı̀n nedeni } \\
\hline Etkili eylem & 761 & 69,0 & 22 & 10,8 & 783 & 60,0 & \multirow{4}{*}{$\begin{array}{r}\text { Pearson } \\
\chi^{2}=2,529 \\
\mathrm{P}<0,0001\end{array}$} \\
\hline Trafik Kazası & 246 & 22,3 & 145 & 71,4 & 391 & 29,9 & \\
\hline Düşme / Sert zemine çarpma & 89 & 8,1 & 36 & 17,7 & 125 & 9,6 & \\
\hline Ateșli silah yaralanması & 7 & 0,6 & - & 0,0 & 7 & 0,5 & \\
\hline Toplam & 1103 & 100,0 & 203 & 100,0 & 1306 & 100,0 & \\
\hline
\end{tabular}

Olguların 715’inde (\% 54,7) kırıkların lineer kırık şeklinde olduğu, 422'sinde (\% 32,3) deplase ve 169'unda (\% 13,0) parçalı kırık olduğu saptandı (Grafik 1). Kırık türleri ile kırık nedenleri arasında anlamlı bir ilişki saptanmıştır (Tablo2,
$\mathrm{P}<0,0001)$. Etkili eylemin, çoğunlukla lineer kırı̆̆a neden olduğu, trafik kazası ve düşmelerin ise daha sık deplase ve parçalı kırığa neden olduğu belirlenmiştir. Ateşli silah yaralanmalarının tümünde parçalı kırık saptanmıştır. 


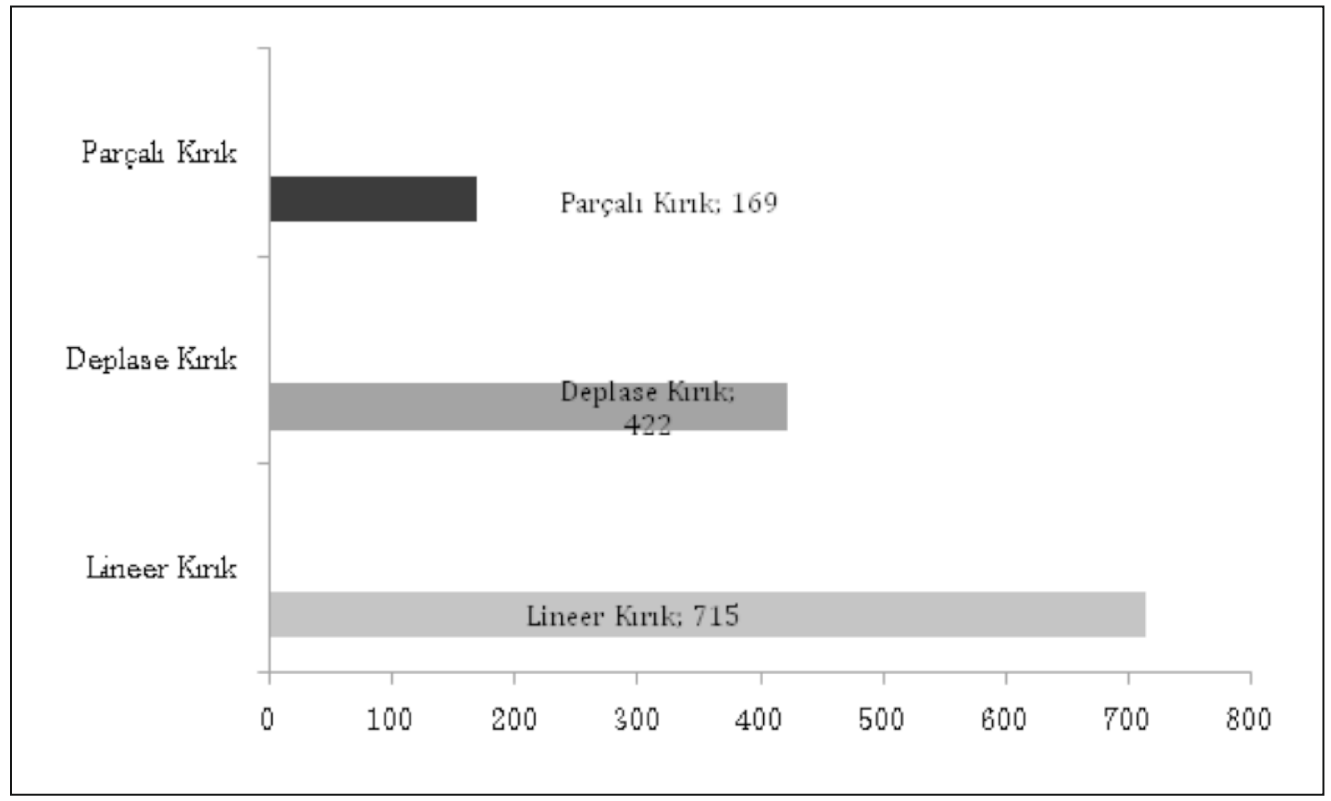

Grafik 1. Kırık türlerinin dağıılımı.

Tablo 2. Olguların kırık türlerinin, kırık nedenlerine göre dağılımları.

\begin{tabular}{|l|c|c|c|c|c|c|}
\hline \multirow{2}{*}{ Kırı̆̆ın nedeni } & \multicolumn{3}{|c|}{ Kırık Türü } & \multicolumn{3}{c|}{ Toplam } \\
\cline { 2 - 7 } & Parçalı & Deplase & Lineer & n & $\%$ & \\
\hline Etkili eylem & 86 & 139 & 558 & 783 & 60,0 & \multirow{2}{*}{ Pearson } \\
\hline Trafik Kazası & 49 & 229 & 113 & 391 & 29,9 & \multirow{2}{*}{$\chi^{2}=2,915$} \\
\hline Düşme / çarpma & 27 & 54 & 44 & 125 & 9,6 & \multirow{2}{*}{$\mathrm{P}<0,0001$} \\
\hline Ateşli silah yaralanması & 7 & - & - & 7 & 0,5 & \\
\hline \multicolumn{1}{|c|}{ Toplam } & 169 & 422 & 715 & 1306 & 100,0 & \\
\hline
\end{tabular}

Burun kırıklarının \% 87'sinde (1137 olgu), kırığın travma ağırlık puanı 1 olup kişinin yaşam fonksiyonlarını hafif derecede etkileyecek nitelikte olduğu, \%13’ünde (169 olgu) ağırlık puanı 2 olup kişinin hayat fonksiyonlarına etkisinin orta derecede olduğu belirlenmiştir.

\section{Tartışma}

Adli Tıp Şube Müdürlügümüzde, birçok şube müdürlüğünde olduğu gibi, genellikle dosya üzerinden rapor düzenlenmektedir. Adli makamlarca tüm evraklar UYAP (Ulusal Yarg1 Ağ1 Projesi) üzerinden veya posta yolu ile tarafımıza gönderilmekte ve kesin rapor talep edilmektedir. Bu nedenle hastanelerden tarafımıza gönderilen tıbbi belgelerin, tam, okunaklı ve kanıta dayalı olması önem taşımaktadır. Ülkemizde yapılan birçok çalışmada, özellikle acil servislerde, adli rapor düzenlenmesi, evrakların saklanması ve gerektiğinde tüm belgelerin adli makamlara ulaştırılmasında birçok aksaklık olduğu vurgulanmıştır (10-14).1306 olguyatravma ağırlığı açısından rapor düzenleyebilmek için toplam 2104 yazışma yapılmıştır. 764 olguda $(\% 58,5) 1 \mathrm{kez} \mathrm{ek}$ yazışma yapılmıştır. Bunların 437'inde (\% 33,5), ön raporunda kırık şüphesi olduğu belirtilmiş, başka bir bilgi veya grafi tarafımıza gönderilmemiştir. 327'sinde (\% 25,0) ön raporda kırık olduğu yazılmış, ancak kırığın türü belirtilmemişve/veya grafi ya da grafilere ait rapor gönderilmemiştir. Bu olgularda, hastanın tüm grafileri veya bunlara ait raporlar ile olayla ilgili tedavi gördüğü sağlık kuruluşundan tüm tıbbi belgelerinin veya hastane dosyasının tarafımıza gönderilmesi istenilmiştir. 17 (\% 1,3) olguda 2 kez ek yazışma yapılmıştır. Bunların 5’inde (\% 0,4) gönderilen bilgiler yeterli olmayıp, kırığın olup olmadığı veya türü açısından konsültasyona ihtiyaç duyulmuştur. 12 'sinde $(\% 0,9)$ ilk yazışmada istenilen hastane dosyası veya grafilerin eksik gönderilmesi nedeniyle tekrar yazışma yapılmıştır. 525 olguda $(\% 40,2)$ ilk düzenlenen raporlar, grafiler ve/veya grafilere ait raporlar tarafımıza eksiksiz olarak gönderilmiş ve direk olarak kesin rapor düzenlenebilmiştir. Konuyla ilgili Kafadar ve arkadaşlarının Elazığ'da yaptığı çalışmada da burun kırıklı olgulara kesin rapor yazma sürecinde, \% 58,4'ünde tekrarlı yazışma gerektiği bildirilmiştir (15).

Burun kırıklarında, kesin raporun yazılabilmesi için kırığın türünün bilinmesi gerekir. Çalışmada olguların \% 24,9'unda 
kırığın tanımlandığı, ancak tipinin belirtilmediği saptanmıştır. Adli raporlar için kullanılmakta olan kılavuzda, burun kırıklarının ağırlığı, ayrıklı veya ayrıksız lineer kırık ve uç kırıklarında bir puan, parçalı kırıklarda iki puan olarak yer almaktadır (9). Sayın ve arkadaşlarının nazal kemik kırıklı olguların değerlendirildiği çalışmalarında, olguların \% 57,6’sinda kapalı non-deplase kırık saptandığı belirtilmiştir (10). Kafadar ve arkadaşlarının yaptığı çalışmada olguların \% 42,7'sinde lineer kırık, \% 37,1'inde deplase kırık, \% 15,7'sinde parçalı kırık olduğu bildirilmiştir (15). Sunulan çalışmada olguların 715’inde (\% 54,7) kırıkların lineer kırık şeklinde olduğu, 422'sinde $(\% 32,3)$ deplase ve $169^{\prime}$ unda $(\% 13,0)$ parçalı kırık olduğu saptanmıştır.

19 olguda (\% 1,5) tıbbi belgeler, grafiler veya tomografiler tarafımızca incelenmiş ancak sonuca varabilmek için Kulak Burun Boğaz uzmanı konsültasyonuna ihtiyaç duyulmuştur.Ancak tarafımızca direk konsültasyon istenilemediği için, adli makamların sağlık kuruluşları ile ayrıca yazışmaları gerekmiştir.

Sunulan çalışmada \% 84,5’inin erkek, \% 15,5’inin kadın olduğu ve yaş ortalamasının $35,3 \pm 11,6$ olduğu belirlenmiştir. Çil ve arkadaşlarının izole nazal kırıklı olguları değerlendirdikleri çalışmada, olguların yaş ortalamasının 21 olduğu ve \% 86,7'sinin erkek olduğu bildirilmiştir (16) Toygar ve arkadaşlarının Ankara'da yaptıkları çalışmada olguların \% 98'inin erkek olduğu bildirilmiştir (8). Sayın ve arkadaşlarının yaptığı çalışmada olguların yaş ortalamasının 28,4 olduğu ve \% 86,2'sinin erkek olduğu belirtilmiştir (10). Hwang ve arkadaşlarının yaptığı çalışmada olguların yaş ortalamasının 21 olduğu saptanmıştır (17). Tezer ve arkadaşlarının nazal kırıklı olguları değerlendirdiği çalışmada olguların \% 75’inin erkek olduğu görülmektedir (18). Adli travmatoloji ile ilgili literatürde olguların genellikle erkek olduğu ve 20-40 yaş grubunun baskın olduğu vurgulamamıștır (19-24). Çocuk yaş grubundaki olguların baskın olarak erkek olduğu, kadınların daha sık trafik kazası sonucu yaralandıkları belirlenmiştir. Bu durum, erkeklerin daha erken yaşlarda dışarıda kavga ortamına karışması ile açıklanabilir. Ancak kadınlarda, aile içi şiddetin gizlenmesi için sağlık kuruluşlarında yanlış öykü verildiğ̈i de göz ardı edilmemelidir.

Sunulan çalışmada saptanan verilerin adli travmatoloji literatürü ile uyumlu olduğu belirlenmiştir $(8,10,15,16)$. Ülkemizde sağlık kuruluşlarında sınırlı sayıda adli tıp uzmanı istihdamı olması nedeniyle, adli tıp hizmetleri genellikle şube müdürlükleri aracılığı ile yürütülmektedir. Adli tıp şube müdürlüklerine gelen ve kesin rapor yazılmasına esas oluşturan hastane evraklarının oldukça yetersiz ve eksik olduğu anlaşılmaktadır. Adli tıp şube müdürlüklerinden direk olarak sağlık kuruluşları ile yazışma yapılamamasının önemli bir eksiklik olduğu düșünülmektedir.

Tüm travmalı olgularda olduğu gibi, burun kırıklı olgularda da ilk başvurdukları sağlık kuruluşlarında düzenlenen ön raporlar ve içerikleri kati rapor düzenlenmesi açısından oldukça önemlidir. Adli tıp şube müdürlüğüne yalnızca "nazal kemikte kırık şüphesi vardır" șeklinde bilgi içeren, grafi, tomografi veya bunların raporlarının gönderilmediği durumlarda, kırığın varlığının veya yokluğunun, varsa tipinin belirlenebilmesi için silsile halinde yerine ulaşabilen yazışma yapılması gerekmektedir. Diğer yandan, sağllk kuruluşlarında radyolojik tetkikler de dahil olmak üzere tetkik sonuçları, özel olarak programlanmış hastane bilgi yönetim sistemi aracıllğıyla bilgisayar ortamında değerlendirilmekte ve saklanmaktadır. Çoğu zaman düzenlenen ön raporlar adli mercilere gönderilirken beraberinde grafiler gönderilmemektedir. Adli Tıp Kurumu ve bağlı birimlerindeki adli tıp uzmanları, diğer sağlık kuruluşlarının hastane bilgi sistemlerine ulaşamamaktadır. Bu grafilerin sonradan yazışma ile istenmesi hastanelerin de iş yükünü arttırmakta, normal prosedür dışında röntgen filmi çıkarmak veya röntgen filmini CD'ye aktarmak durumunda kalmaktadırlar. Sağlık Bakanlığı hastanelerinde görev yapmakta olan adli tıp uzmanları, hastalara yapılan tetkik ve tedavileri bilgisayar ortamından ulaşabilmekte, gerektiğinde diğer branş hekimlerinden konsültasyon isteyebilmekte, kısa sürede nitelikli rapor düzenleyebilmektedir. Ancak, hastanelerdeki adli tıp uzmanları da UYAP sistemine dahil olmadıkları için raporları kısa sürede düzenleseler bile prosedüral olarak evrak geliş-gidişi ve raporların adli mercilere ulaşması zaman almaktadır. Uzun vadede, sağlık kuruluşlarında adli tıp uzmanı istihdamının artırılması, kısa vadede ise illerde sağllk kurulușlarına ait veri sistemlerine adli tıp şube müdürlüklerinin de entegre edilmesi gerektiği düşünülmektedir. Tüm adli tıp uzmanlarının, hem sağlık sistemi hem de UYAP sistemine entegre olmaları, yarg1 sürecini hızlandıracağından yargı reformu çerçevesinde tartıșılmalıdır.

\section{Kaynaklar}

1. Kılıçoğlu SS. Mikroskobi düzeyinde kırık iyileşmesi. Ankara Üniversitesi Tip Fakültesi Mecmuası 2002;55(2):143-50

2. Mathog Robert H, Arden Richard L, Marks Steven C. Burun ve Paranasal Sinüs Travmaları, Nobel Tıp Kitabevleri Ltd; 1995. p.2137.

3. Yi CR, Kim YJ, Kim H, Nam SH, Choi YW. Comparison study of the use of absorbable and nonabsorbable materials as internal splints after closed reduction for nasal bone fracture.Arch Plast Surg. 2014 ;41(4):350-4.

4. Kaul RP, Sagar S, Singhal M, Kumar A, Jaipuria J, Misra M. Burden of maxillofacial trauma at level 1 trauma center.Craniomaxillofac Trauma Reconstr. $2014 ; 7(2): 126-30$.

5. Karagama YG, Newton JR, Clayton MG. Are nasal fractures being referred propriately from the accident and emergency department to ENT Injury 2004;35:968-71. 
6. Yabe T, Ozawa T, Sakamoto M, Ishii M. Pre- and postoperative Xray and computed tomography evaluation in acute nasal fracture. Ann Plast Surg 2004;53:547-53.

7. Mondin V, Rinaldo A, Ferlito A. Management of nasal bone fractures. Am J Otolaryngol 2005;26:181-5.

8. Toygar M, Şenol E, Can Ö. Burun Kemik Kırıklarının Adli Tip Açısından Değerlendirilmesi. Turkiye Klinikleri J of Foren Med 2007, 4: 17-22.

9. Balcı Y, Güzel S, Çetin G. Yeni Türk Ceza Kanunu'nda tanımlanan yaralama suçlarının adli tıp açısından değerlendirilmesi. In; Editör; Balcı Y. Herkes için adli tıp cep kitabı. Eskişehir Osmangazi Üniversitesi Yayınları Eskișehir 2008:203-35.

10. Sayın İ, Ekizoğlu O, Yazıcı ZM, Erdim İ, Kayhan FT. Nazal fraktürlerin değerlendirilmesi ve adli tıp yaklaşımı. Adli Tıp Bülteni 2010;15(3):99-103.

11. Tuğcu H, Yorulmaz C, Ceylan S, Baykal B, Celasun B, Koç S. Acil servis hizmetine katılan hekimlerin, acil olgularda hekim sorumluluğu ve adli tıp sorunları konusundaki bilgi ve düşünceleri. Gülhane Tip Dergisi 2003; 4 (2): 175-9.

12. Salaçin, S., Tuncer, İ ., Erkocak, E.U.: Türkiye'de Mezuniyet Öncesi ve Sonrası Adli Tıp Eğitiminin Sorunları. Adli Tıp Dergisi. 1993;9(1-4):17-22.

13. Karbeyaz K, Gündüz T, Akkaya H, Urazel B, Kökçüoğlu MA. Adli raporlara dikkat; Eskişehir deneyimi. Sürekli Tıp Eğitimi Dergisi 2012;21(5): 292-6.

14. Çolak B, Demirbaş İ, Albayrak Ü. Geçici adli raporların önemi; Olgu sunumu. Sürekli Tıp Eğitimi Dergisi 2005;14(7): 161-4.

15. Kafadar H, Kafadar S. Burun kemiği kırıklarının Türk Ceza Kanunu çerçevesinde değerlendirilmesi. Adli Tıp Bülteni 2013;18(1):20-24.
16. Çil Y, Kahraman E. An analysis of 45 patients with pure nasal fractures. Ulus Travma Acil Cerrahi Derg 2013;19 (2):152-6

17. Hwang K, You SH, Kim SG, Lee SI. Analysis of nasal bone fractures; a six-year study of 503 patients. J Craniofac Surg 2006;17(2):261-4

18. Tezer MS, Dede D, Yılmaz Y, Sarı K, Sayın B, Yıldırım M, Ünal A. Nazal fraktürlerin tespitinde direk grafiler ve bilgisayarlı tomografinin yeri. Turk Arch Otolaryngol 2006;44(3):137-40.

19. Bilgin NG, Dokgöz H, Kar H. Eski ve yeni Türk Ceza Yazası'na göre düzenlenen adli raporların karşılaștırılması. Adli Tıp Bülteni 2006;11(2):64-70.

20. Küçüker H, Aksu A. 1997-2001 yıllarında Fırat Üniversitesi hastanesi acil servisine başvuran trafik kazası olgularının değerlendirilmesi. Acil Tıp Dergisi 2003;3(2):11-15.

21. Küçüker H. Acil servise gelen ölümle sonuçlanmayan travmatik adli olguların ve raporların değerlendirilmesi. Acil Tıp Dergisi 2003;3(4):19-23.

22. Altun G, Azmak D, Yllmaz A, Yllmaz G. Trakya Üniversitesi tıp fakültesi acil servisine başvuran adli olguların özellikleri. Adli Tıp Bülteni 1997;2(2):62-6.

23. Ceekin N, Savran B, Hilal A, Gülmen MK, Alper B, Bilgin N, Özzdemir MH. Adana'da kaza dışı yaralanma olgularında adli raporların değerlendirilmesi. Adli Tıp Bülteni 2000;5(2):130-133.

24. Bilgin NG, Canbaz H, Mert E. Mersin Üniversitesi Tıp Fakültesi Hastanesi acil servisine başvuran adli olguların özellikleri. Adli Bilimler Dergisi 2004;3(4):37-44 